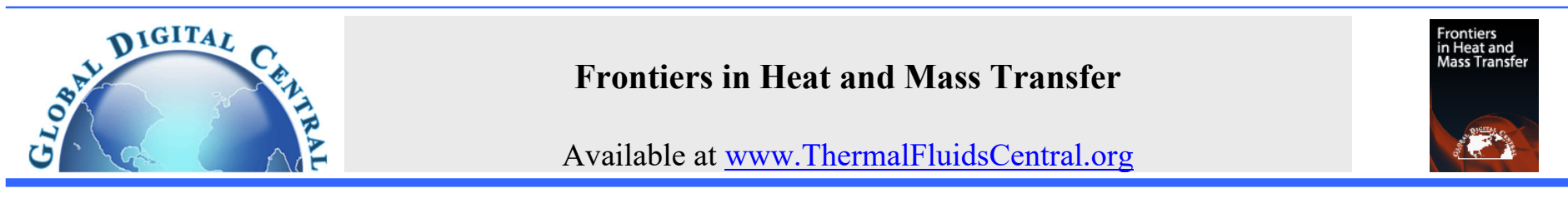

\title{
EXPERIMENTAL STUDY OF CONVECTIVE HEAT TRANSFER OF ALUMINA OXIDE NANOFLUIDS IN TRIANGLE CHANNEL WITH UNIFORM HEAT FLUX
}

\author{
Kaprawi Sahim*, Dewi Puspitasari, Nukman \\ Mechanical Engineering, Engineering Faculty, Sriwijaya University, Indralaya, Indonesia
}

\begin{abstract}
The recent trend application of the nanofluids is used in some industrial equipment such as tube heat exchanger, double pipe exchanger and shell-tube type heat exchanger. The Triangle tubes may be used in the heat exchanger. Thus, this experimental study reports the convective heat transfer performance of the aluminum oxide-water nanofluids flowing in the triangle channel. In this study, the amount of the volume fraction of the $\mathrm{Al}_{2} \mathrm{O}_{3}$ used was $0.1 \%, 0.2 \%$, and 0.3 respectively in base-water as the nanofluids and the Reynolds numbers were varied from about 1000 to 7000 . The channel was heated by the electric wire coiled along the channel with constant heat flux. The length and the hydraulic diameter of the triangular channel were $750 \mathrm{~mm}$ and $7.1 \mathrm{~mm}$ respectively. The DC variable speed pump was used to drive the nanofluids in the channel. Five thermocouples were soldered at the outer surface of the channel to measure the surface temperature. At the inlet and outlet of the channel were attached the thermocouples to measure the inlet and the outlet temperature of the nanofluids. The heat absorbed by the fluid was then released in the cooling tower which used an induced draft fan to convince that the nanofluids temperature decreased before entering the inlet section of the channel. The heat transfer characteristics of the nanofluids are compared to that of pure water. The results show that the heat transfer increase with the increase of the Reynolds number and the volume fraction. The increase of heat transfer varies from about $11 \%$ to $36 \%$.
\end{abstract}

Keywords: Volume fraction, heat transfer coefficient, Nusselt number, entry length.

\section{INTRODUCTION}

Nanofluids are suspensions of nanoparticles in fluids that show significant enhancement in heat transfer and are highly suited to application in different types of heat exchangers in industries, such as plate heat exchangers, shell-and- tube heat exchangers, compact heat exchangers and double-pipe heat exchangers (Huminic et al., 2012). Many empirical studies were carried out regarding the heat transfer of diverse nanofluids. The heat transfer increase of nanofluids flowing in the triangle channel with vortex generator is shown experimentally by Ahmaed et al. (2015). The highest heat transfer increase is $33.22 \%$ for alumina oxide nanofluid. A convective heat transfer can be enhanced with nanoparticles suspended in base water since it increases the thermal conductivity of the water-nanoparticles suspension, furthermore, the thermal conductivity depends on the particle volume fraction as reported by Xuan and Li (2000). In convective heat transfer, the important parameters that influence significantly its performances are heat transfer coefficient and Reynolds number, but in convective nanofluids heat transfer, the heat transfer characteristics depend also on the volume fraction of nanoparticles in which it increases with the increase of volume fraction (Singh and Gupta, 2016). For laminar flow, the influence of concentration of $\mathrm{TiO}_{2}$ nanoparticle in water-based fluid which flows in the triangle duct with uniform heat flux is given by Jodat (2014).

The numerical study of nanofluid Alumina oxide in the triangle duct of the fully developed section is presented by Haghighatkhah et al. (2018). Heris et al. (2012) used nanofluids $\mathrm{CuO}$ in the region of hydrodynamically developed and thermally developing flow of a triangle duct to investigate numerically the heat transfer characteristics. Heris et al. (2007) used a dispersion model to show numerically heat transfer performance along with the developing flow of circular tube. They demonstrate that the convective heat transfer decreases rapidly with the increase of tube length. Muzychka and Yovanovich (2004) gave a mathematical model for heat transfer characteristics in the developing flow of non-circular channels. For low Reynolds numbers, especially for $\operatorname{Re}=100$, Manca et al. (2014) give numerically the heat transfer in triangle duct of $\mathrm{Al}_{2} \mathrm{O}_{3}$ water-based nanofluids from the developing to the fully developed flow section. They show that heat transfer decrease rapidly starting from Nusselt number $\mathrm{Nu} \approx 10$ in the developing section and decrease very slowly in a region of fully developed flow. Wen et al. (2004) conducted investigations to explore the convection heat transfer in the entry length region of the circular pipe by the use of de-ionized water with $\mathrm{Al}_{2} \mathrm{O}_{3}$ nanoparticles. The highest heat transfer occurred at a narrow entry length and then it decreases rapidly with the increase of tube length. For fully developed flow in a circular pipe, the heat transfer increases linearly with Reynolds number and it reaches 4.65 at about $\mathrm{Re}$ $=2000$ (Ting and Hou, 2015).

The study of convective heat transfer of fluid with and without the addition of nanoparticles is reached in a fully developed laminar flow. The considerable enhancement is observed for fluid with the addition of nanoparticles particularly at high Reynolds numbers as shown by Heris et al.(2011). Hwang et al. (2009) showed that the addition of concentration of nanoparticle Alumina oxide $0.3 \%$ in pure water enhances heat transfer performance up to $8 \%$ in a fully developed laminar flow regime. The convective heat transfer profile in circular, rectangular, and triangle duct has similar distributions but its values are different about $15 \%$ each other. However, the triangle duct has the highest value (Saleh et al., 2018). The heat transfer of nanofluids influenced by the Peclet number in which it increases linearly with the Peclet number (Ting and Hou, 2016). Qi et al. (2020) investigated heat transfer performances of $\mathrm{SiO}_{2}$ water-based nanofluids flowing in a 
triangular duct with turbulators. Qi et al. (2018) investigated that the twisted tape structures in the triangle tube could enhance the thermal performances. They presented that the increase of a mass fraction of nanoparticles increases the heat transfer. $0.5 \%$ of a mass fraction have the most significant effect on heat transfer enhancement. Edalati et al. (2012) used $\mathrm{CuO}$ /water nanofluids in a laminar flow under uniform heat flux conditions through the triangle duct. It is reported an enhancement of $41 \%$ in the thermal characteristics for a $0.8 \% \mathrm{CuO} /$ water nanofluid when compared to pure water. In the turbulent flow of the triangular duct, Yazan Taamneh et al. (2019) presented a considerable increase in heat transfer when pure water was added nanoparticle $\mathrm{Al}_{2} \mathrm{O}_{3}$. This enhancement achieved about $18 \%$ for a concentration of nanoparticles of $0.05 \%$. The use of alumina oxide nanoparticle in water under laminar and turbulence flow can enhance the heat transfer performance as much as $40 \%$, while the thermal conductivity increase was under $15 \%$ (Yu et al., 2008). Generally, the convective heat transfer a 15-40\% enhancement was recorded with the oxides nanoparticles (Okonkwo et al., 2020). Astuti et al. (2019) used nanofluids $\mathrm{TiO}_{3}$, $\mathrm{Al}_{2} \mathrm{O}_{3}$, and $\mathrm{Cu}$ in the prediction of heat transfer performance from an accelerated vertical plate and then Wakif et al. (2019) used the Alumina-nanofluids in studying the stability of thin boundary layer. Nanoparticles used in enhancing the heat transfer are in size less than $50 \mathrm{~nm}$ as summarized by Shanthi et al. (2012). In case of diameter variation of a conduit has no effect on the energy efficiency in a laminar flow (Sharma et al., 2020).

From the above literature surveys, this study presents the heat transfer characteristics of the nanofluids alumina oxide flowing in the triangular channel. The effect of small variations of nanoparticle concentration and Reynolds variations are presented in order to investigate the enhancement of convective heat transfer

\section{EXPERIMENTAL SET-UP}

\subsection{Preparation of Nanofluids}

We used the nanoparticle of $\mathrm{Al}_{2} \mathrm{O}_{3}$ or alumina. The nanoparticles of Alumina in powder form have the size of around 20-30 nm and delivered from Wuhuhangchen Company Ltd. The distilled water as base fluid was used in the experimental observations having a volume of 3 liters and then alumina nanoparticle with volume fraction variation of $0.1 \%, 0.2 \%$, and $0.3 \%$ were suspended in distilled water as the base fluid. The exact weight of alumina nanoparticles corresponding to volume fraction was calculated. By using a mini digital scale. The alumina nanoparticles were weighed to obtain the desired weight resulted from the calculation. The exact amount of the $\mathrm{Al}_{2} \mathrm{O}_{3}$ needed for the experimental measurements is calculated from the relation as follow (Al-Waeli et al., 2017).

$$
m_{p}=\rho_{p}\left(\frac{\varphi}{1-\varphi}\right)\left(\frac{m_{f}}{\rho_{f}}\right)
$$

In this relation, $\varphi$ is the volume fraction, $\rho_{\mathrm{p}}$ and $\rho_{\mathrm{f}}$ are the density of nanoparticle and water-base fluid respectively and $m_{\mathrm{f}}$ is the amount of water-based fluid. The mass of nanoparticle was mixed gradually into distilled water and then it was stirred with a magnetic stirrer. After that, the mixer of $\mathrm{Al}_{2} \mathrm{O}_{3}$ /water nanofluid was homogenized for about 10 minutes by using an ultrasonic homogenizer system (Sonicator 80). It was observed that no sedimentations were observed for all volume fractions.

The specification of $\mathrm{Al}_{2} \mathrm{O}_{3}$ particles as follows:

Density : $3970 \mathrm{~kg} / \mathrm{m}^{3}$

Colour: white

Size : 20-30 nm

Morphology : hexagonal

Purity : $99.99 \%$

\subsection{Triangle Channel}

The triangle tube is made up of copper material with an inside length of each side is $11.2 \mathrm{~mm}$ and a thickness of $0.5 \mathrm{~mm}$. The hydraulic diameter is $7.1 \mathrm{~mm}$ and the length of the tube is $750 \mathrm{~mm}$. The tube was coiled by the nichrome wire heater of size 26 AWG and then the heater was covered by ceramic insulation to avoid heat losses to the ambient. The schematic longitudinal view of the channel is presented by Fig. 1 and the photo is shown in Fig. 2a.

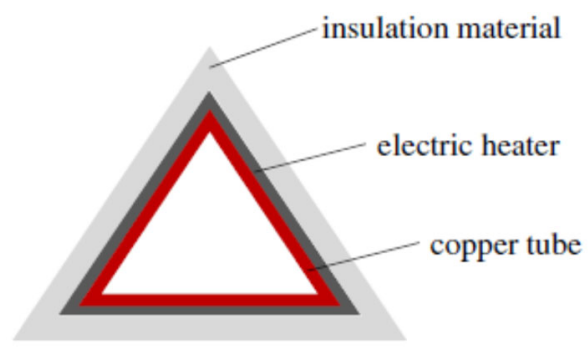

Fig. 1 Longitudinal view of the channel

\subsection{Measurement procedure}

The schematics arrangement of the experimental apparatus is given by Fig. 2a. After fabrication of the apparatus, the photo of main element is shown by Fig. $2 b$.

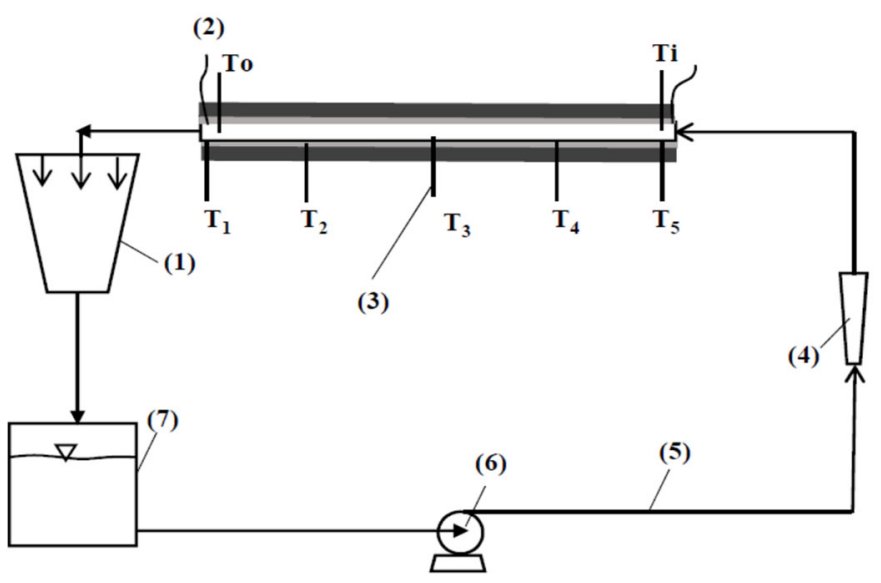

(a)

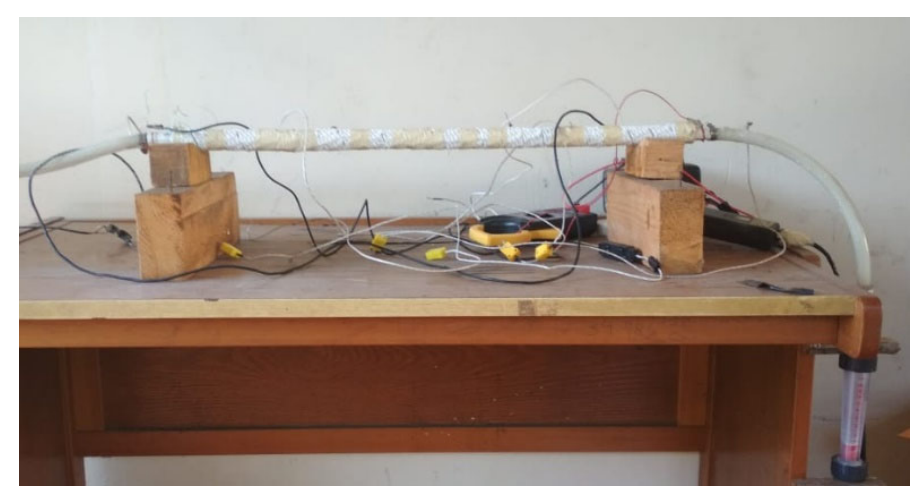

(b)

Fig. 2 Photo and schematic arrangement of apparatus

The nanofluids $\mathrm{Al}_{2} \mathrm{O}_{3}$ based water in the reservoir (7) is pumped by a small centrifugal pump (6) of maximum capacity $600 \mathrm{l} / \mathrm{hr}$ which is powered by a DC variable electric motor. The voltage regulator regulates the voltage entering the motor and as the result the speed of the pump 
changes, then the desired flow rate is obtained. The rotameter with accuracy $\pm 4 \%$ (4) of maximum capacity $160 \mathrm{l} / \mathrm{hr}$ is attached to the discharged line (5) of the pump. The temperatures were measured with the digital thermocouple type-K TM $902 \mathrm{C}$ with an accuracy of $0 \mathrm{C}$ to $500 \mathrm{C}+(0.75 \%+1 \mathrm{C})$. Fives temperature sensors $\left(T_{1}, . ., T_{5}\right)$ were soldered on the pipe wall and two sensors $\left(T_{\mathrm{i}}, T_{\mathrm{o}}\right)$ were in the flow line. The outside wall of the channel was heated by an AC current with a uniform heat flux of $340 \mathrm{~W}$. The hot flow of nanofluids after flowing in the tube (2), entered the cooling tower unit (1). To keep the constant temperature of the flow, the spray type cooling system was used in the cooling tower. At the top of the cooling tower was installed an axial fan to induce hot air after receiving heat from the fluid spray. The nanofluids with low temperature entered the reservoir (7) and it is ready to be repumped. The measurements were repeated three times for each flow rate and carried out under constant heat flux.

\subsection{Data Processing}

The data resulted from the measurements are calculated from the equation (2) to (13). Reynolds number is calculated from the following relation:

$$
\operatorname{Re}=\frac{\rho u D_{h}}{\mu_{n f}}
$$

where $D_{\mathrm{h}}$ ia hydraulic diameter and it is defined by

$D_{h}=\frac{4 A_{c}}{P}$

and dynamic viscosity is given by

$\mu_{n f}=\frac{\mu_{f}}{(1-\varphi)^{2.5}}$

The electric heater of the $\mathrm{AC}$ is calculated

$$
Q_{e}=I . V
$$

The effective heating energy received from the fluid is given by the following relation

$$
Q_{f}=m c_{p}\left(T_{o}-T_{i}\right)
$$

Specific heat of nanofluid is as follows

$c_{\mathrm{p}}=(1-\varphi) c_{\mathrm{pf}}+\varphi c_{\mathrm{pp}}$

The density of nanofluid is given by the following relation

$\rho=(1-\varphi) \rho_{\mathrm{f}}+\varphi \rho_{\mathrm{p}}$

Average temperature of nanofluids is calculated as follows

$T_{n f}=\frac{T_{i}+T_{o}}{2}$

Average outside surface temperature is as follows

$T_{s o}=\left(\sum_{i=1}^{n} T_{o l}\right) / n$

Average inside surface temperature is calculated from

$T_{s i}=T_{s o}-\frac{Q_{f} \ln (r o / r i)}{2 \pi k_{c} L}$

where ro and ri are the outside and inside hydraulic radius of the channel. Coefficient of heat transfer is calculated as follows.

$h=\frac{Q_{f}}{\pi D_{h} L\left(T_{s i}-T_{f}\right)}$
Nusselt number is calculated from the following formula

$N u=\frac{h D_{h}}{k_{n f}}$

\section{RESULT AND DISCUSSIONS}

Two parameters were selected to investigate the influence of nanoparticle Alumina oxide added into the distilled water on the forced convective heat transfer; firstly, the influence of volume fraction of nanoparticles, and secondly, the influence of Reynolds number. Some important enhancement characteristics of heat transfer performance is observed. In Fig. 3, starting view of convective heat transfer coefficient characteristics of the pure water, the considerable increases of heat transfer coefficient are observed for nannofluids with concentration of $0.1 \%, 0.2 \%$ and $0.3 \%$ since the curves profiles of nanofluids are greater than that of pure water. The greater the volume fraction, the higher the enhancement. The coefficients of convective heat transfer increase with the increase of Reynolds number. For high Reynolds number, the difference of coefficient are more clear than that for low Reynolds numbers. The Reynolds numbers studied in this work is from about 1500 to 7500 . So the flow characteristics started from laminar to turbulent. The curves seem to be continuous from laminar to turbulent and no discontinuous data at about $\mathrm{Re}=2300$. The experimental investigation clearly show that the significant enhancement in heat transfer coefficient though for a small concentration of nanoparticles compared with the pure water. Taking an example for instance, at $\operatorname{Re}=2000$, by the interpolation of the curves, it is found that the heat transfer enhancement is about $11.3 \%$ for the nanofluid with $\varphi=0.1 \%$ as compared with that of pure water. The enhancement is higher for higher Reynolds number. At a low Reynolds number, the heat transfer enhancements are small for all concentrations of nanoparticles. It may be due to the existence of three narrow sections of the triangle tube. In this section, the flow slows down, and hence the coefficient of heat transfer enhancement is low.

Fig. 4 shows the Nusselt number variations for different volume concentrations of nanoparticle and pure water. The curve profiles are similar to the heat transfer coefficient (Fig. 3) since the Nusselt number is a dimensionless parameter of convection heat transfer. It is clear that a considerable difference in heat transfer between the pure water $(\varphi=0 \%)$ and the nanofluids $\mathrm{Al}_{2} \mathrm{O}_{3}$ based water for all Reynolds numbers. At low Reynolds number, the differences of Nusselt number are small among the nanofluids, but the curves have a tendency to increase with the increase of Reynolds number. When the Reynolds number increases, the significant differences appear and the differences increase with the increase of Reynolds number. Comparing with the pure water, the Nusselt number of nanofluids base water enhance. For instance, at $\mathrm{Re}=$ 2000 and $\varphi=0.1 \%$, the enhancement is $11.34 \%$. This enhancement increase to $17.17 \%$ for $\varphi=0.2 \%$ and $18.79 \%$ at the same Reynolds number as shown by Fig. 5 which presents the ratio of Nusselt of nanofluids and to that of the pure water. As shown in Figure that the ratio value starts from unity and the numbers after the decimal point represent the increase of the heat transfer in percent. It is clear that the increases much larger for high concentrations of nanoparticles in the base fluid. At small flow rates, the sedimentation of nanoparticles may arise in the nanofluids flow, and hence, at a low Reynolds numbers, a lower heat transfer increase is low. For higher Reynolds number these enhancements increase, for example at $\mathrm{Re}=6000$, the enhancement is $21 \%$ for $\varphi=0.1 \%, 25.15 \%$ for $\varphi=0.2 \%$ and $33.48 \%$ for $\varphi=0.3 \%$ respectively. In the range of $\varphi=0.1 \%$ to $0.3 \%$ and the Reynolds number from 1500 to 7500 , the range of increase is from $11 \%$ to $36 \%$. The increase of the volume fraction of nanoparticle enhance the heat transfer rate since the nanofluids absorbed more heat to be transferred. Morever, by increasing the Reynolds number, the flow become a turbulent that make the chaotic movement of the nanoparticles and increases the intensity of mixing therefore produces higher heat transfer rate. 


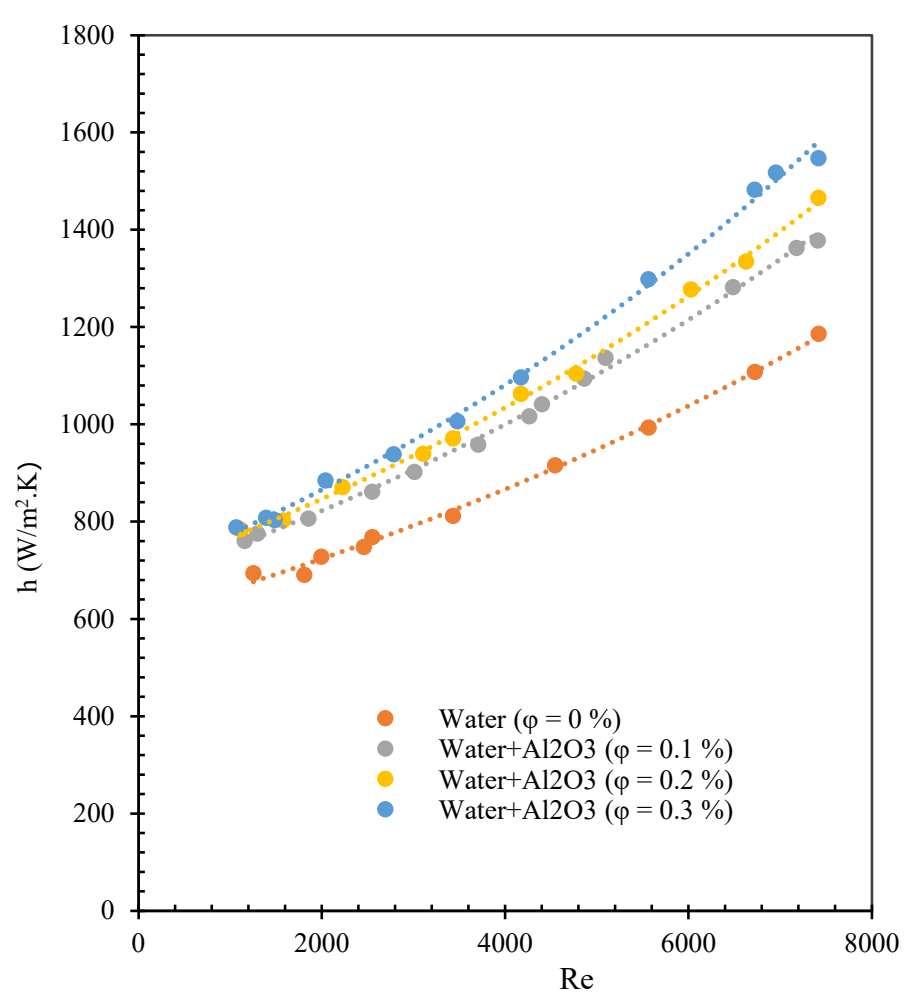

Fig. 3 Heat transfer coefficient

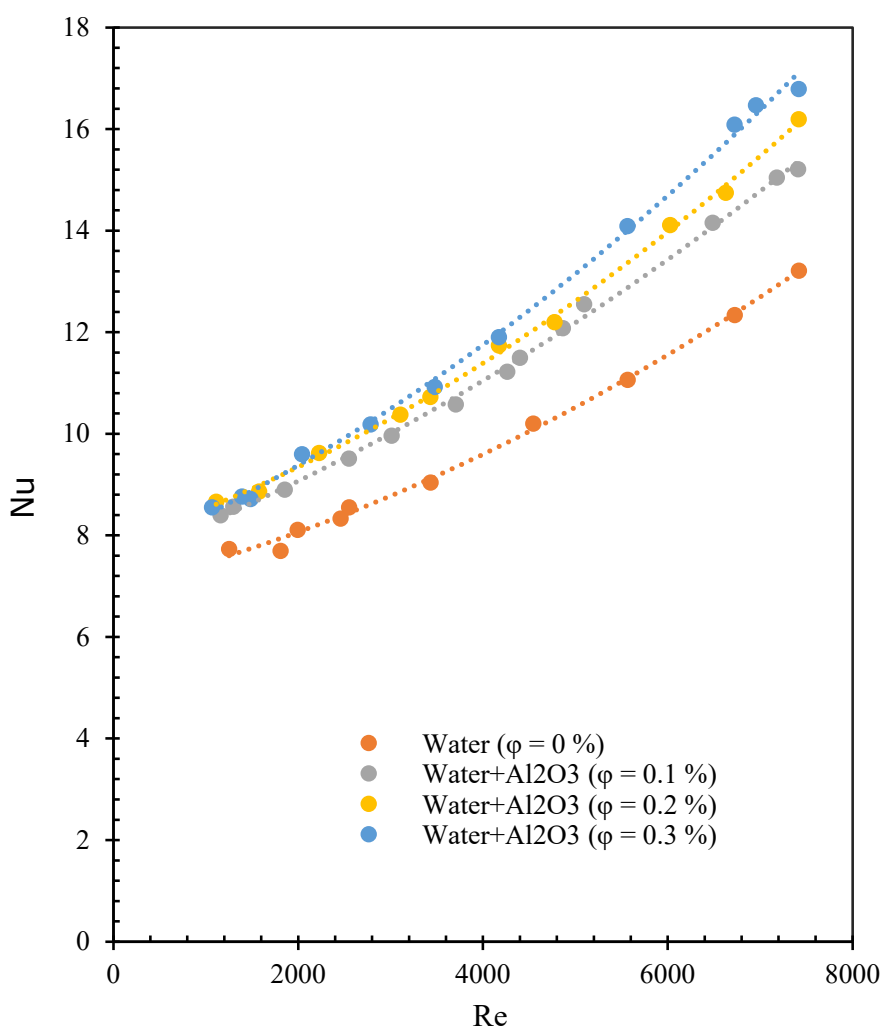

Fig. 4 Nusselt number

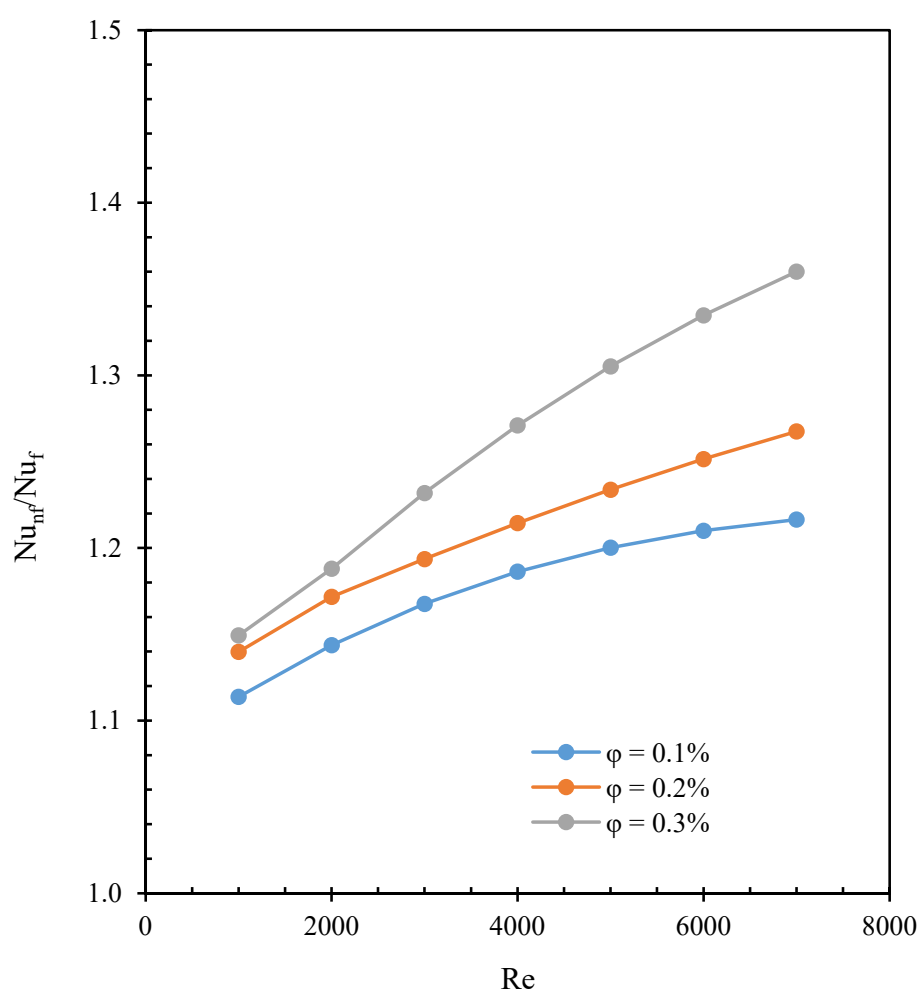

Fig. 5 Nusselt ratio

\section{CONCLUSIONS}

Forced convective heat transfer characteristics of three different concentrations of the nanoparticle $\mathrm{Al}_{2} \mathrm{O}_{3}$ in pure water in triangle tube flow with constant heat flux have been investigated experimentally. The results indicate that adding nanoparticles to the base fluid improves the heat transfer when compared with pure water. The adding of volume fraction of nanoparticles in pure water enhance the heat transfer performance and the enhancement increases with the increase of Reynolds number. The increase of heat transfer varies from about $11 \%$ to $36 \%$. The enhancement of the heat transfer is low in laminar flow and it increases in turbulent flow regime.

\section{ACKNOWLEDGEMENTS}

This work is supported by Sriwijaya University through penelitian Unggulan Profesi

\section{NOMENCLATURE}

A cross-section, $\mathrm{m}^{2}$

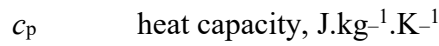

$D_{\mathrm{h}} \quad$ hydraulic diameter, $\mathrm{m}$

$h$ convective heat transfer coeffiecient, W.m ${ }^{2}$.K- ${ }^{1}$

I electric current, Ampere

$k$ thermal conductivity of nanofluids, W.m- ${ }^{-1} \cdot \mathrm{K}^{-1}$

$L \quad$ length of tube, $m$

$m \quad$ mass rate of fluid, $\mathrm{kg} \cdot \mathrm{s}^{-1}$

$n \quad$ Number of temperature sensors

$\mathrm{Nu} \quad$ Nusselt number

$P \quad$ wetted perimeter, $\mathrm{m}$

$r \quad$ radius of tube, $\mathrm{m}$

$T \quad$ temperature, $\mathrm{K}$ 


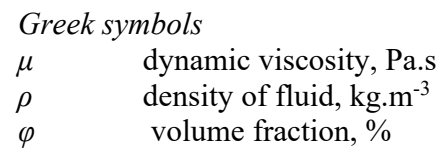

\section{Subscripts}

$p \quad$ nanoparticle

si inside surface

ol local outside surface

so average outside surface

$i \quad$ inlet

$o \quad$ outlet

$n f \quad$ nanofluids

$f \quad$ fluid based water

\section{REFERENCES}

Ahmed, H.E., Ahmed, M.I., and Yusoff, M.Z., 2015, "Heat transfer enhancement in a triangular duct using compound nanofluids and turbulators". Applied Thermal Engineering, 91, 191-201. https://doi.org/10.1016/j.applthermaleng.2015.07.061

Al-Waeli, A.H.A., Chaichan, M.T., Kazem, H.A., and Sopian, K., 2017, "Comparative study to use nano-(A12O3, $\mathrm{CuO}$, and $\mathrm{SiC})$ with water to enhance photovoltaic thermal PV/T collectors". Energy Conversion and Management, 148, 963-973.

https://doi.org/10.1016/j.enconman.2017.06.072

Edalati, Z., Zeinali Heris, S., and Noie, S.H., 2012, "The study of laminar convective heat transfer of $\mathrm{CuO} /$ water nanofluid through an equilateral triangular duct at constant wall heat flux". Heat Transfer - Asian Research, 41(5), 418-429.

https://doi.org/10.1002/htj.21011

Astuti, H., Sri P., Kaprawi S., 2019, "Natural convection of nanofluids past an accelerated vertical plate with variable wall temperature by presence of the radiation". Frontiers in Heat and Mass Transfer, 3(13), $1-8$.

https://doi.org/10.5098/hmt.13.3

Haghighatkhah, A., Ahmadi-Danesh-Ashtiani, H., and Amiraslani, K., 2018, "Numerical study of the heat transfer rate of nano-fluid flow in a channel with a triangular cross-section in the presence of a magnetic field". Universal Journal of Mechanical Engineering, 6(4), 55-62. https://doi.org/10.13189/ujme.2018.060401

Heris, S., Talaii, E., and Noie, S., 2012, "CuO/water nanofluid heat transfer through triangular ducts". Iranian Journal of Chemical Engineering, 9(1), 23-32.

Heris, S.Z., Esfahany, M.N., and Etemad, G., 2007, "Numerical investigation of nanofluid laminar convective heat transfer through a circular tube". Numerical Heat Transfer; Part A: Applications, 52(11), $1043-1058$.

https://doi.org/10.1080/10407780701364411

Heris, S.Z., Noie, S.H., Talaii, E., and Sargolzaei, J., 2011, "Numerical investigation of al2o3/water nanofluid laminar convective heat transfer through triangular ducts". Nanoscale Research Letters, 6(1), 179.

https://doi.org/10.1186/1556-276X-6-179

Huminic, G., and Huminic, A., 2012, "Application of nanofluids in heat exchangers: A review". Renewable and Sustainable Energy Reviews, 16(8), 5625-5638.

https://doi.org/10.1016/j.rser.2012.05.023
Hwang, K.S., Jang, S.P., and Choi, S U.S., 2009, "Flow and convective heat transfer characteristics of water-based $\mathrm{Al} 2 \mathrm{O} 3$ nanofluids in fully developed laminar flow regime". International Journal of Heat and Mass Transfer, 52(1-2), 193-199. https://doi.org/10.1016/j.ijheatmasstransfer.2008.06.032

Jodat, A., 2014, "Numerical and Experimental Study of Laminar Forced Convective Heat Transfer of Tio 2 -Water Nanofluid in Triangular Duct". International Journal of Artificial Intelligence and Mechatronics, 3(3), 107-111.

Manca, O., Nardini, S., Ricci, D., Tamburrino, S., and Jaluria, Y., 2014, "A numerical analysis on nanofluid mixed convection in triangular crosssectioned ducts heated by a uniform heat flux". Advances in Mechanical Engineering, 7(1).

https://doi.org/10.1155/2014/292973

Muzychka, Y.S., and Yovanovich, M.M., 2004, "Laminar forced convection heat transfer in the combined entry region of non-circular ducts". Journal of Heat Transfer, 126(1), 54-61.

https://doi.org/10.1115/1.1643752

Okonkwo, E.C., Wole-Osho, I., Almanassra, I.W., Abdullatif, Y.M., and Al-Ansari, T., 2020, "An updated review of nanofluids in various heat transfer devices". In Journal of Thermal Analysis and Calorimetry (Issue March). Springer International Publishing.

https://doi.org/10.1007/s10973-020-09760-2

Qi, C., Fan, F., Pan, Y., Liu, M., and Yan, Y., 2020, "Effects of turbulator with round hole on the thermo-hydraulic performance of nanofluids in a triangle tube". International Journal of Heat and Mass Transfer, 146, 118897

https://doi.org/10.1016/j.ijheatmasstransfer.2019.118897

Qi, C., Liu, M., Luo, T., Pan, Y., and Rao, Z., 2018, "International Journal of Heat and Mass Transfer Effects of twisted tape structures on thermo-hydraulic performances of nanofluids in a triangular tube". International Journal of Heat and Mass Transfer, 127, 146-159. https://doi.org/10.1016/j.ijheatmasstransfer.2018.08.017

Saleh, A., Rasheed, S., and Smasem, R., 2018, "Convection Heat Transfer in a Channel of Different Cross Section Filled With Porous Media". Kufa Journal of Engineering, 09(02), 57-73.

https://doi.org/10.30572/2018/kje/090205

Shanthi R, Shanmuga Sundaram Anandan, V.R., 2012, "Heat Transfer Enhancement using Nanofluids". Thermal Science, 16(2), 423-444. https://doi.org/10.2298/TSCI110201003S

Sharma, L., Kumar, S., Thakur, R., Goel, B., Suri, A.R.S., Thapa, S., Kumar, N., Maithani, R., and Kumar, A., 2020, "A review on exergy analysis of nanofluid flow through several conduits". Frontiers in Heat and Mass Transfer, 14, 1-15.

https://doi.org/10.5098/hmt.14.30

Singh, V., and Gupta, M., 2016, "Heat transfer augmentation in a tube using nanofluids under constant heat flux boundary condition: A review". Energy Conversion and Management, 123, 290-307. https://doi.org/10.1016/j.enconman.2016.06.035

Taamneh, Y., Kabeel, A.E., Prakash, N., Sathyamurthy, R., and Chamkha, A. J., 2019, "Thermal and hydraulic characteristics of a triangular duct using an A12O 3 nanofluid in a turbulent flow regime". Heat Transfer - Asian Research, 48(6), 2639-2654.

https://doi.org/10.1002/htj.21521 
Ting, H., and Hou, S., 2016, "Numerical Study of Laminar Flow and Convective Heat Transfer Utilizing Nanofluids in Equilateral Triangular Ducts with Constant Heat Flux". Materials, 9(7), 576.

https://doi.org/10.3390/ma9070576

Ting, H., and Hou, S., 2015, "Numerical Study of Laminar Flow Forced Convection of Water- $\mathrm{Al}_{2} \mathrm{O}_{3}$ Nanofluids under Constant Wall Temperature Condition". Mathematical Problems in Engineering, 2015. https://doi.org/10.1155/2015/180841

Wakif, A., Boulahia, Z., Amine, A., Animasaun, I.L., Afridi, M. I., Qasim, M., and Sehaqui, R., 2019, "Magneto-convection of aluminaWater nanofluid within thin horizontal layers using the revised generalized Buongiorno's model". Frontiers in Heat and Mass Transfer, 12 .

https://doi.org/10.5098/hmt.12.3
Wen, D., and Ding, Y., 2004, "Experimental investigation into convective heat transfer of nanofluids at the entrance region under laminar flow conditions". International Journal of Heat and Mass Transfer, 47(24), 5181-5188.

https://doi.org/10.1016/j.ijheatmasstransfer.2004.07.012

Xuan, Y., and Li, Q., 2000, "Heat transfer enhancement of nanofluids". International Journal of Heat and Fluid Flow, 21(1), 58-64. https://doi.org/10.1016/S0142-727X(99)00067-3

Yu, W., France, D.M., Routbort, J.L., and Choi, S.U.S., 2008, "Review and comparison of nanofluid thermal conductivity and heat transfer enhancements". Heat Transfer Engineering, 29(5), 432-460. https://doi.org/10.1080/01457630701850851 